\title{
From Design to Application of a Decision-support System for Integrated River-basin Management
}

\author{
Jean-Luc de Kok • Sebastian Kofalk • \\ Jürgen Berlekamp • Bernhard Hahn · Herman Wind
}

Received: 2 July 2007 / Accepted: 9 September 2008 /

Published online: 22 October 2008

(C) The Author(s) 2008. This article is published with open access at Springerlink.com

\begin{abstract}
During the last two decades several integrated tools have been developed to make the existing scientific knowledge available to river managers and assist them with the formulation and evaluation of alternative combinations of measures. Yet, few practical examples of embedding of these instruments in river management organizations can be observed so far. This paper identifies the possible organizational, technical, and scientific factors that may form an obstacle for the design and application of a Decision-Support System (DSS) for river-basin management by analyzing the interaction between the different participants in the Elbe DSS
\end{abstract}

J.-L. de Kok $(\bowtie)$

Unit Spatial Environmental Modelling,

Flemish Institute for Technological Research (VITO),

Boeretang 200, $2400 \mathrm{Mol}$, Belgium

e-mail: jeanluc.dekok@vito.be

J.-L. de Kok

Water Engineering \& Management Group, University of Twente,

PO Box 217, 7500 AE, Enschede, The Netherlands

S. Kofalk

German Federal Institute of Hydrology (BfG), PO Box 200253,

56002 Koblenz, Germany

J. Berlekamp

Institute for Environmental Systems Research,

Department of Mathematics and

Computer Science, University of Osnabrück,

49076 Osnabrück, Germany

B. Hahn

Research Institute of Knowledge Systems, PO Box 463,

6200 AL, Maastricht, The Netherlands

H. Wind

Infram, PO Box 16, 8316 ZG, Marknesse, The Netherlands 
project. In particular attention is paid to the software engineering aspects of the design process. In order to start an integrated approach to deal with conflicting river strategies a project to develop a prototype tool for integrated management of the Elbe catchment was initiated, which includes functionalities related to inland navigation, water quality, flood safety, and vegetation ecology. The problems faced in the German part of the Elbe catchment range from poor navigation conditions and flooding vulnerability to a need to restore and maintain the natural state of the floodplains. Several river engineering works such as large-scale dike shifting, channel dredging, and large-scale retention are in a planning or implementation stage. From the beginning of the project onwards attention was paid to the involvement of potential end-users and key stakeholders in the design process. The experience of the project is that internal consistency of models and data, effective communication, and functional flexibility are essential to warrant a proper balance between scientific standards, the availability of models, and the requirements of users. This facilitates the design process and improves the chance of successful implementation.

Keywords Decision-support system $\cdot$ Elbe $\cdot$ River-basin management . System design $\cdot$ Model integration $\cdot$ Appropriate modeling

\section{Introduction}

With the adoption of the EU Water Framework Directive (EU 2000; Moss 2004) all European countries have committed themselves to a river-basin approach. The formulation and implementation of Integrated River Basin Management (IRBM) strategies in accordance with both the national legislation and the EU directive is not a straightforward task. Finding a proper balance between the interests of different stakeholders requires understanding the effects of combined measures on multiple river functions. Uncertain future conditions related to, for example, changing political priorities, economic development and climate change, influence the outcome of proposed alternatives, and thereby their ranking. Although the decisions are inherently a political matter there is a growing awareness that plans need scientific underpinning and the support of local stakeholders prior to implementation. To help bridge the gap between the scientific knowledge and demand for information it is desirable to combine a wide range of expertise and data and make it available for the analysis and presentation of promising strategies for IRBM. A DSS for river basin management enables-for different scenarios-the comparison of river strategies based on the effects on multiple objectives. It can be used to support the planning and implementation of measures (Giupponi 2007; Volk et al. 2007) and the communication between the stakeholders and between the researchers involved. The different purposes of a DSS for IRBM include: analysis of different management alternatives, communication, education, and knowledge management (Loucks 1995; Hahn and Engelen 2000; Zhu and Dale 2000; Westmacott 2001; De Kok and Wind 2003; Legris et al. 2003; Maurel et al. 2007; Giupponi 2007). During the last decades a variety of tools were developed to assist water managers with strategic planning tasks (Berlekamp et al. 2005; Giupponi 2007). Many of these instruments take an integrated perspective on problems by combining scientific knowledge from multiple disciplines to understand the relevant processes and effects of different combinations 
of measures. Recently, some interesting examples were presented of the crosslinkage between process analysis and software design of a DSS for IRBM (Castelletti and Soncini-Sessa 2007; Castelletti et al. 2007; Dietrich et al. 2007). Despite of the involvement of potential users during the design and effort spent on generic frameworks for integrated water management (Van Waveren et al. 1999; Mysiak et al. 2005; Refsgaard et al. 2005; Giupponi et al. 2007; Scholten et al. 2007) there are still few practical examples of river organizations that use these instruments for policy analysis and communication purposes (Gourbesville 2008). Walker (2002) examined the failure of decision-support projects in the field of rural resource management and attributes the lack of acceptation of DSS by users to inflexibility, inaccessibility, irrelevance of the instruments, a lack of confidence, or institutional and political barriers. Many of these problems have been reported elsewhere in the literature (Ubbels and Verhallen 2000; Westmacott 2001; De Kok and Wind 2003; Legris et al. 2003; Uran and Janssen 2003; Mysiak et al. 2005; Borowski and Hare 2007; Brugnach et al. 2007; Olsson and Andersson 2007) in one form or another and were also experienced with the development of a pilot DSS for the Elbe river. Here, the different roles and interaction of all participants in DSS design are examined in detail for a concrete case study in order to arrive at practical guidelines for the complete DSS life cycle. In particular attention is paid to the software engineering aspects of the design process. The paper is organized as follows. To provide a basis for the user perspective Section 2 analyzes the potential role of a DSS to support decision making related to integrated river-basin management. Section 3 describes the design process and structure of the Elbe-DSS in more detail. Section 4 discusses the procedural and technical aspects of the software engineering approach that was followed to design the DSS in comparison to other approaches. Section 5 takes the design history of two key components of the DSS, the risk assessment model (De Kok and Huang 2005) and point-source pollution model GREAT-ER (Matthies et al. 2001; Berlekamp et al. 2007), to illustrate the problems that can be experienced when models have to be (re)designed for application in a DSS. Guidelines for more efficient (in terms of the process) and more effective (in terms of acceptance) DSS design are formulated in Section 6, which is followed by the conclusions section.

\section{Functions of a DSS for River-basin Management}

In general river basin planning should be aimed at multiple purposes, integrated development, and generating acceptance for interventions (Downs et al. 1991; Barrow 1998; Moss 2004). To understand how river managers can be supported by using DSS tools it is necessary to examine the cycle of policy planning and implementation (Fig. 1). The policy cycle consists of six steps (Hoekstra 2005), which are to take place in an iterative rather than a sequential way. A key activity in the planning phase, aimed at identifying and analyzing management alternatives, is that of policy analysis (Miser and Quade 1985). This requires scientific knowledge and expertise to describe the effects of different combinations of measures and scenarios on selected indicators. During the implementation phase it is important to gain support for a policy.

This conceptual model of control still leaves open the question to what extent and how a DSS can support river basin managers. The role of information and support for effective control in water management can be formulated in terms of 


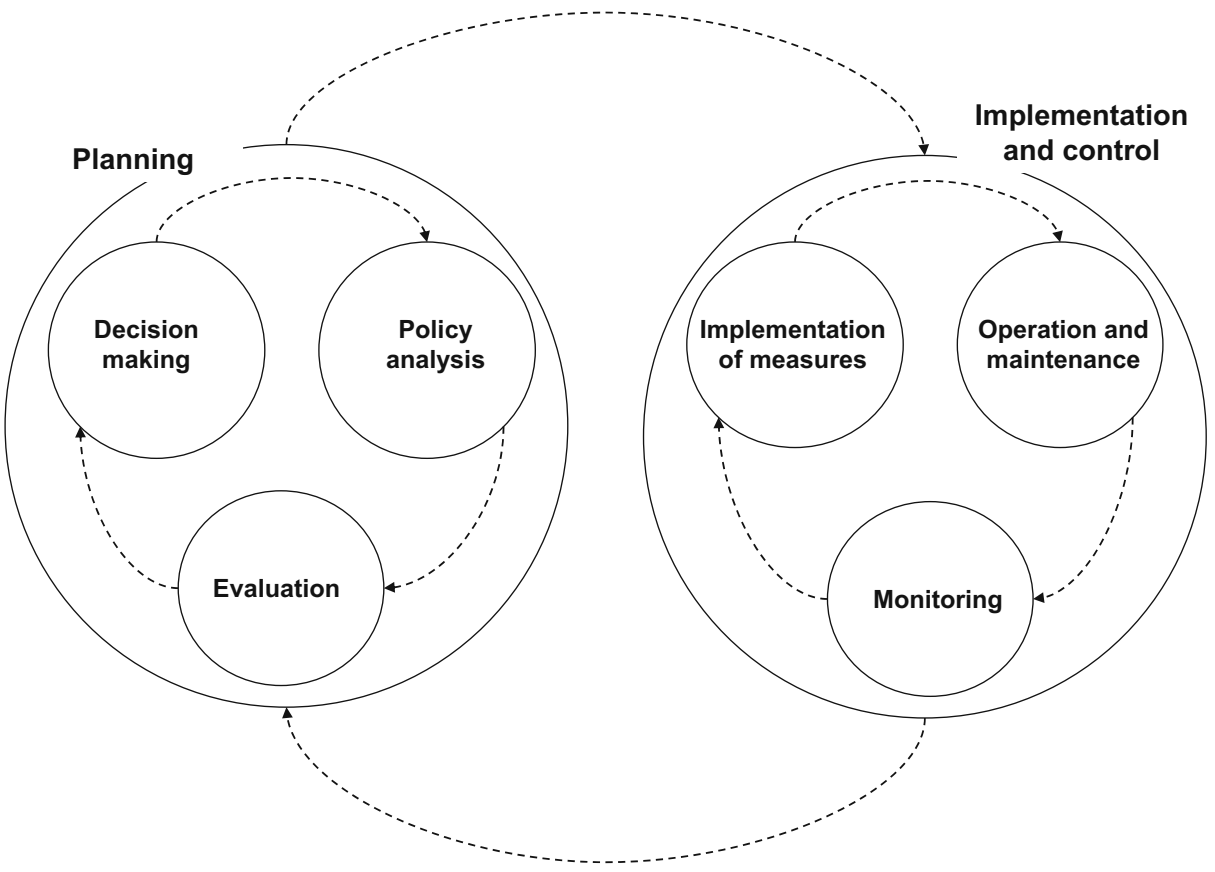

Fig. 1 The policy cycle (Hoekstra 2005)

three conditions (De Leeuw 1974; Verbeek and Wind 2001). Consistency refers to a rational problem solving process, which pertains to the planning cycle in Fig. 1, aimed at formulating clear objectives and actions that can be taken to achieve these. But the complexity of IRBM is also a consequence of the need to take different, possibly conflicting interests into account. Therefore, gaining support is the second condition for a management plan to be implemented effectively. The supply of information is the third condition: both the formulation of a consistent management strategy and the creation of support benefit from adequate information. Depending on whether knowledge concerning the effects or the acceptance of a policy is more important, the policy making process should focus on consistency-oriented activities (such as setting the objectives, finding measures, and modeling the effects) or support-oriented activities (such as negotiation and communication) according to Verbeek and Wind (2001). Gaining societal and institutional support by interactively demonstrating the different effects of promising alternatives at an early stage, for example, is a task that could be addressed with a DSS, provided that there is no alternative (Walker 2002). This task is clearly different from comprehensive analysis of a management strategy by a person who is to provide a river manager with detailed information. In the past DSS have been defined as computer-based tools that assist managers with solving ill-structured problems (Morton 1971; Sprague and Carlson 1982; Loucks 1995). Although the analysis of different solutions to a problem is an obvious purpose, various other uses for a DSS have been identified as well (Loucks 1995; Walker 2002; Janssen et al. 2006):

- Discussion support

- Learning environment, educational tool 
- Institutional capacity building

- Data storage, model library

The basic components of a DSS are the user-interface, data base, and an inference engine based on models of different scientific disciplines (Sprague and Carlson 1982). Typically a DSS has a practical purpose, which distinguishes it from integrated assessment studies (Scrase and Sheate 2002) with a more scientific aim. The criticism (Westmacott 2001; Walker 2002) with respect to the usefulness of a DSS for resource management is mostly related to a lack of relevance for the envisaged users and unclear role for the instrument. Walker (2002) concludes that capacity building by learning may be a more appropriate function than influencing the decision making process itself, whereas (Westmacott 2001) emphasizes the communication supporting function of a DSS. Therefore, the objectives and structure of the Elbe-DSS must be elaborated before discussing the problems related to its design and application.

\section{The Elbe-DSS as a Tool for IRBM}

\subsection{The River Elbe and Organizational Aspects of River Basin Management}

The Elbe is one of the largest rivers in Central Europe with a catchment area of about $148,000 \mathrm{~km}^{2}$ and a length of $1100 \mathrm{~km}$ (Fig. 2). Two-thirds of the catchment lies in Germany. The modeled German section of river has a length of $586 \mathrm{~km}$ between the Czech-German border and the weir at Geesthacht, near the city of Hamburg. The elevation ranges between sea level near Hamburg up to $1000 \mathrm{~m}$ in the mountains near the Czech border. The land use in the catchment is mainly agricultural with some large cities such as Dresden and Magdeburg along the river. The mean annual precipitation is approximately $700 \mathrm{~mm}$ per year (HAD 2000) with a maximum precipitation of over $1200 \mathrm{~mm}$ per year in the mountainous areas of the catchment. The water quality in the river is affected by agricultural runoff, while settlements and manufacturing within the river basin formed important point sources of pollution in the past. In terms of shipping density the river Elbe is an important waterway in Germany, although not comparable to the Rhine (http://www.elwis.de). Planned and ongoing river engineering works are aimed at improving the navigability of the river by groyne restoration, and reducing the risk of flooding by large-scale dike displacement and renaturation of the floodplains. Several sections of the upper and middle part of the river have been designated as protected nature reserves with vegetation types that form a habitat for rare fauna. It is not yet clear to what extent the hydromorphological consequences of river engineering works will affect the vegetation conditions along the river. The formulation of an optimal management strategy requires in-depth understanding of the interaction of these measures with the social-economic, ecological, and physical processes at different scale levels (Scholten et al. 2005).

At the national level a distinction can be made between the administrative and practical competences related to waters in Germany. This means that different parties are involved in the decision processes. With regard to their function as waterways for navigation the major rivers are under federal ownership. Management obligations for navigation are assigned to the Federal Ministry of Transport, Building and Urban Affairs (BMVBS) with the Federal Waterways and Shipping Administration (WSV) 


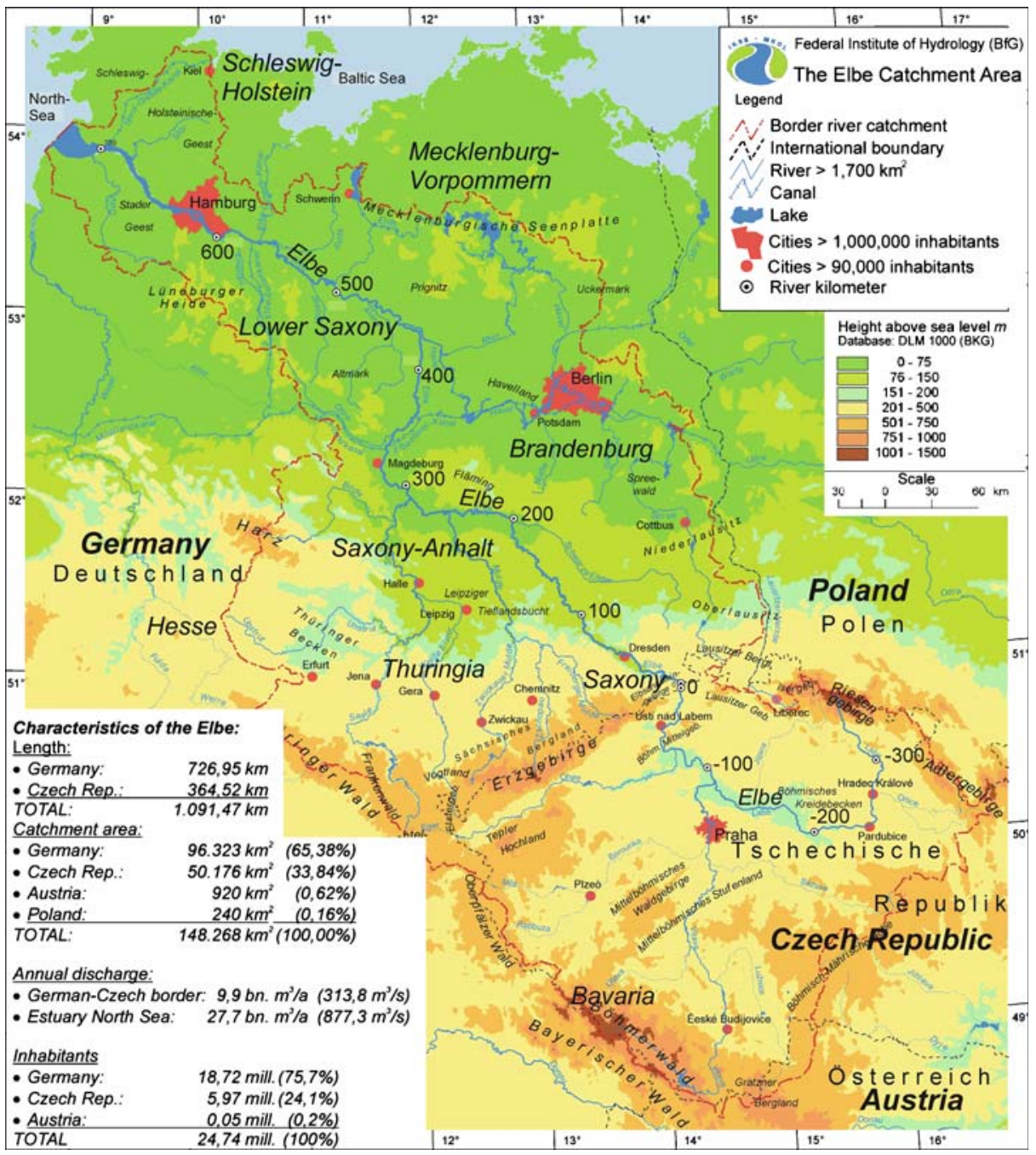

Fig. 2 The Elbe river basin (Federal Institute of Hydrology (BfG), Digital Landscape Model DLM 1000 (Federal Agency for Cartography and Geodesy (BKG))

as executive body. The WSV is in charge of the maintenance and development of the Federal waterways with the exclusive purpose of providing save and efficient conditions for navigation. The WSV does not have any competences with regard to other water management issues, including the implementation of the European Water Framework Directive (EU-WFD). Subordinated to and consulting the BMVBS are research oriented institutes such as the Federal Institute of Hydrology (BfG) and the Federal Waterways Engineering and Research Institute (BAW). The Federal Ministry of the Environment, Nature Conservation and Nuclear Safety (BMU) is responsible for nature protection at the national level and the national coordination and fulfillment of the EU-WFD guidelines towards the European Commission. The Ministry is supported by its subordinated institutes such as the Federal En- 
vironmental Agency (UBA) and Federal Agency for Nature Conservation (BfN), working on national regulations and concepts on these fields. In this respect, the $\mathrm{BfG}$ is also working for the BMU, by monitoring the water quality and carrying out environmental research. Generally, the 16 German Federal states (Länder) are in charge of all water management issues (nature conservation, flood protection, recreation, drinking and process water supply, energy production/cooling water, or fisheries) within their respective boundaries. This includes the implementation of the EU-WFD for all German waters. Ten Länder and the Federal government founded the River Basin Commission Elbe in 2003 in order to put the EU-WFD into practice. The establishment of the biosphere reserve "River Landscape Elbe" by the UNESCO forms a basis for sustainable development of the floodplains along the River Elbe, which is organized by the Länder and local municipalities. The objectives of the reserve focus on the integration of nature protection, agriculture, forestry, and water management purposes. An administrative stakeholder is the International Commission for the Protection of the Elbe River (ICPE), in which mainly Germany and the Czech Republic cooperate. The ICPE aims to support different, mainly environmentally oriented goals and flood protection. Water-related NGOs are also important because these have the right to comment and intervene in planning processes such as environmental impact assessment procedures. Finally, different interest groups related to agriculture, navigation, harbors, and other issues pursue their goals.

\subsection{Objectives of the Elbe-DSS}

Multidisciplinary knowledge was needed to improve the decision making and meet various requirements related to the transportation function, the fulfillment of the EU-Water Framework Directive (WFD) and Species and Habitats Directive (EU 1992), but also to respond to unexpected events like the River Elbe flood in the year 2002. A gap in the knowledge could (and can) be observed in the impact assessment of measures with a catchment oriented perspective, including national economics. Therefore, the BfG initiated the development of a prototype DSS using the River Elbe as example. The project started in the spring of 2002 and was completed by the end of 2005 with the delivery of a prototype DSS for the Elbe River, its floodplains, and the catchment (Berlekamp et al. 2005). The modeled area covers the German section of the River Elbe and river basin, roughly between the CzechGerman border and the city of Hamburg. The principal objective of the Elbe-DSS is to demonstrate the capability to support management tasks related to problems in the fields of:

- Water quality related to land use and waste water treatment

- Flood risk

- River navigation

- Increasing the ecological value of the riverscape

The Elbe-DSS combines knowledge, methodologies and tools of different institutions. Depending on their respective competences the different described administrational decision makers and interest groups are either "potential" or already practical users. The indicators that are taken into account as decision criteria and the way these have been implemented in the Elbe-DSS will be described in Section 3.5. 


\subsection{System Structure}

The Elbe-DSS is founded on the hydraulic, ecological and other data, models and knowledge that had been collected and developed during the research program Elbe Ecology and were available from different organizations involved in management of the river basin (Gruber and Kofalk 2001; Hattermann et al. 2007). In this way high quality and up-to-date models and data have been made available to the managers of the River Elbe. In view of the multi-objective nature of the DSS and scale differences of models and data, the choice was made to use a modular design with four interacting modules pertaining to three scale levels: the river basin and corresponding river network, the main channel (including floodplains), and a river section (selected locations along the river). Figure 3 shows the qualitative system diagram that reflects the modular structure of the DSS.

The catchment module uses a conceptual rainfall-runoff model (Krysanova et al. $1999)$ and $1 \times 1 \mathrm{~km}$ grid to describe the effect of non-point source pollution on the quality of the runoff under various hydrological conditions and management practices (Behrendt et al. 1999; Matthies and Berlekamp 2006). In the river network module the complete river network is divided into $2 \mathrm{~km}$ reaches to describe the dispersal of point-source pollution (Matthies et al. 2001; Matthies and Berlekamp 2006). Both modules interact with the other two modules of the DSS, the channel and river section module, via the discharge statistics. These are derived from the time series for the average daily discharge which are obtained with the rainfall-runoff model. The focus of the catchment and network module of the Elbe DSS lies on

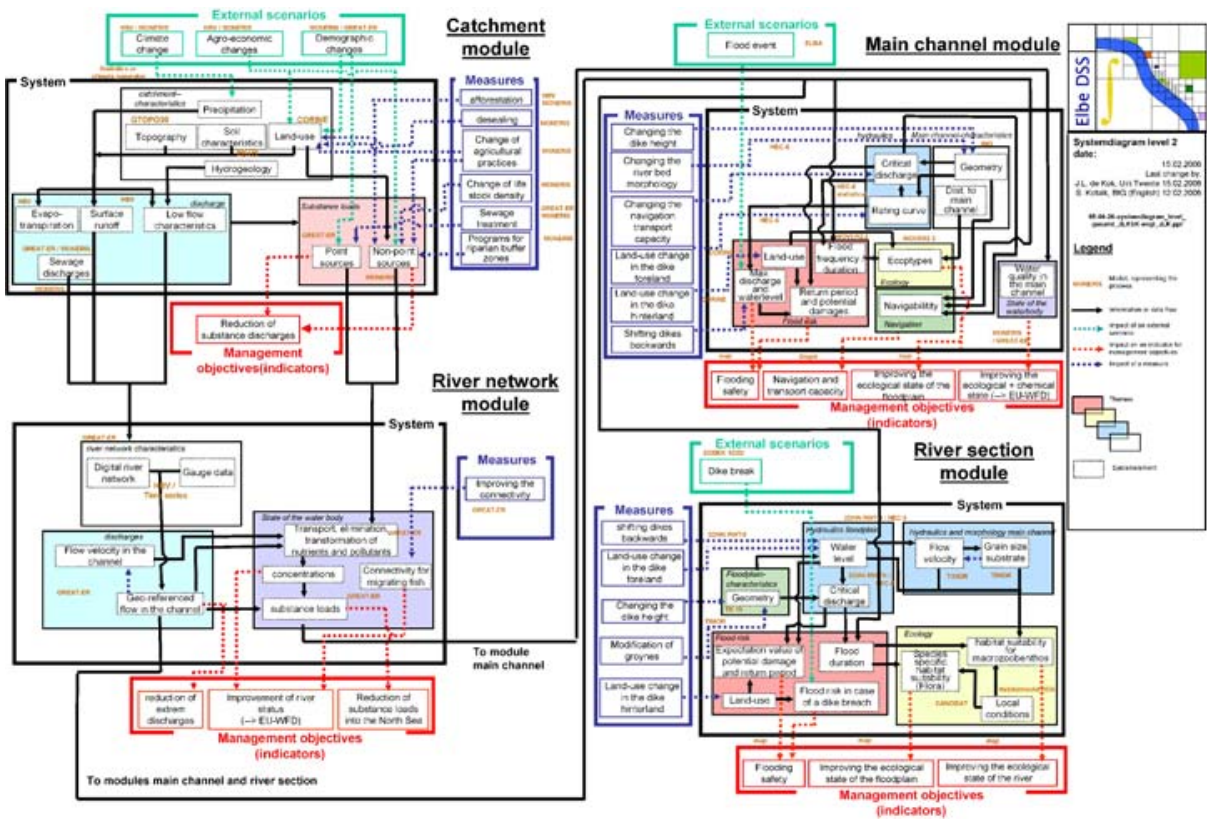

Fig. 3 Qualitative system diagram for the final DSS prototype with measures, scenarios, and management indicators 
the combined basin-scale effect of changes in agro-economic policy and agricultural practices on the water quality. An agricultural sector model (Henrichsmeier et al. 1996) is used to describe the development of the agricultural production under different scenarios for taxes and subsidies. Product-nitrogen price functions are included to account for changes in fertilizing practices. Examples of various measures which can be taken to examine the influence on the diffuse expel of nutrients are eco-farming, crop combination changes, fertilization timing, and drainage practices. The channel module describes the navigation conditions, flood safety, and floodplain vegetation at a strategic scale level for a $500 \mathrm{~km}$ section of the river, with a spatial resolution of $100 \times 100 \mathrm{~m}$. The river section module describes the flood risk and vegetation ecology at selected locations with a spatial resolution in the order of 1-10 m. For example, maps of the maximum flow velocities in case of a dike breach and the floodplain ecology at species level for selected locations are described in the channel module of the Elbe-DSS. Although the introduction of the modules made it possible to incorporate processes at different relevant scale levels this raised the difficulty of how to couple the modules in a consistent manner. For example, the channel and river section module are largely based on probabilistic model concepts and take the daily discharge statistics from the other two modules. Nevertheless, some processes such as the dike breach simulations in the river section module and flood risk assessment in the channel module required deterministic flood events as input. These can be selected as separate external scenarios by the users.

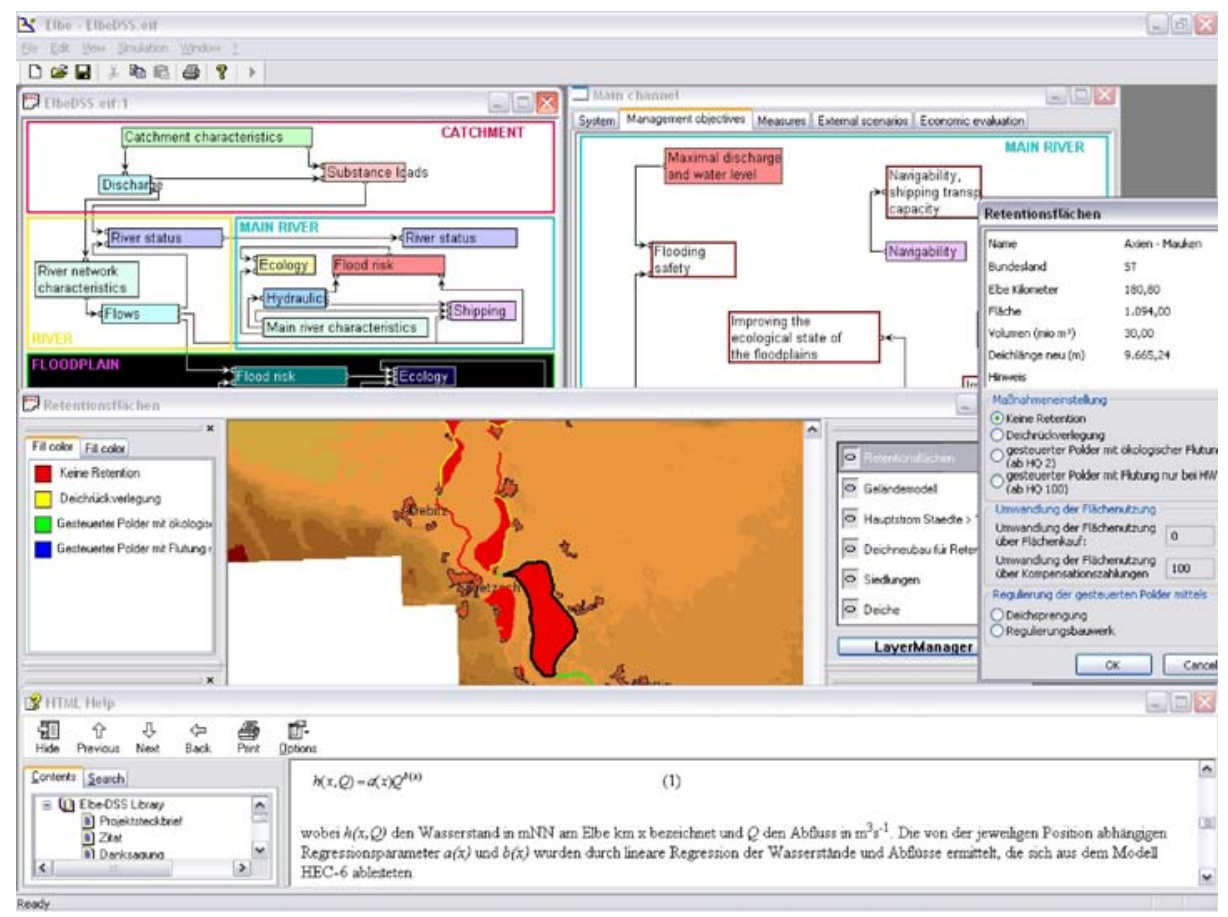

Fig. 4 User interface of the Elbe-DSS prototype with easy access to measures, objectives, and scenarios 


\subsection{User Interface}

To reflect the system hierarchy of the DSS the user interface is an interactive representation of the qualitative system diagram and provides easy access to the four key components of the DSS: model system, external scenarios, measures, and the indicators corresponding to the management objectives. Depending on the theme of interest the user can either obtain information or enter changes via dialogue boxes. Figure 4 provides an example screenshot for the flood risk assessment in the channel module of the DSS, retention being one of the measures to mitigate the flood risk.

Valuable features of the DSS are the presentation of results in the form of interactive maps, which allow for user changes, the possibility to explore the effects of various combinations of measures, and the online documentation of the complete DSS design, including the data, knowledge, scientific model assumptions, and key indicators. Examples of aggregated information provided to the users are given in Figs. 5, 6 and 7 .

Table 1 shows the effect of 14 controlled retention polders on the flood risk for flood events with different return periods. The combination of polders and way these can be operated can be chosen by the users via the map editor (see Fig. 4). The damage reduction is particularly large for the 200-year flood event. The effect on

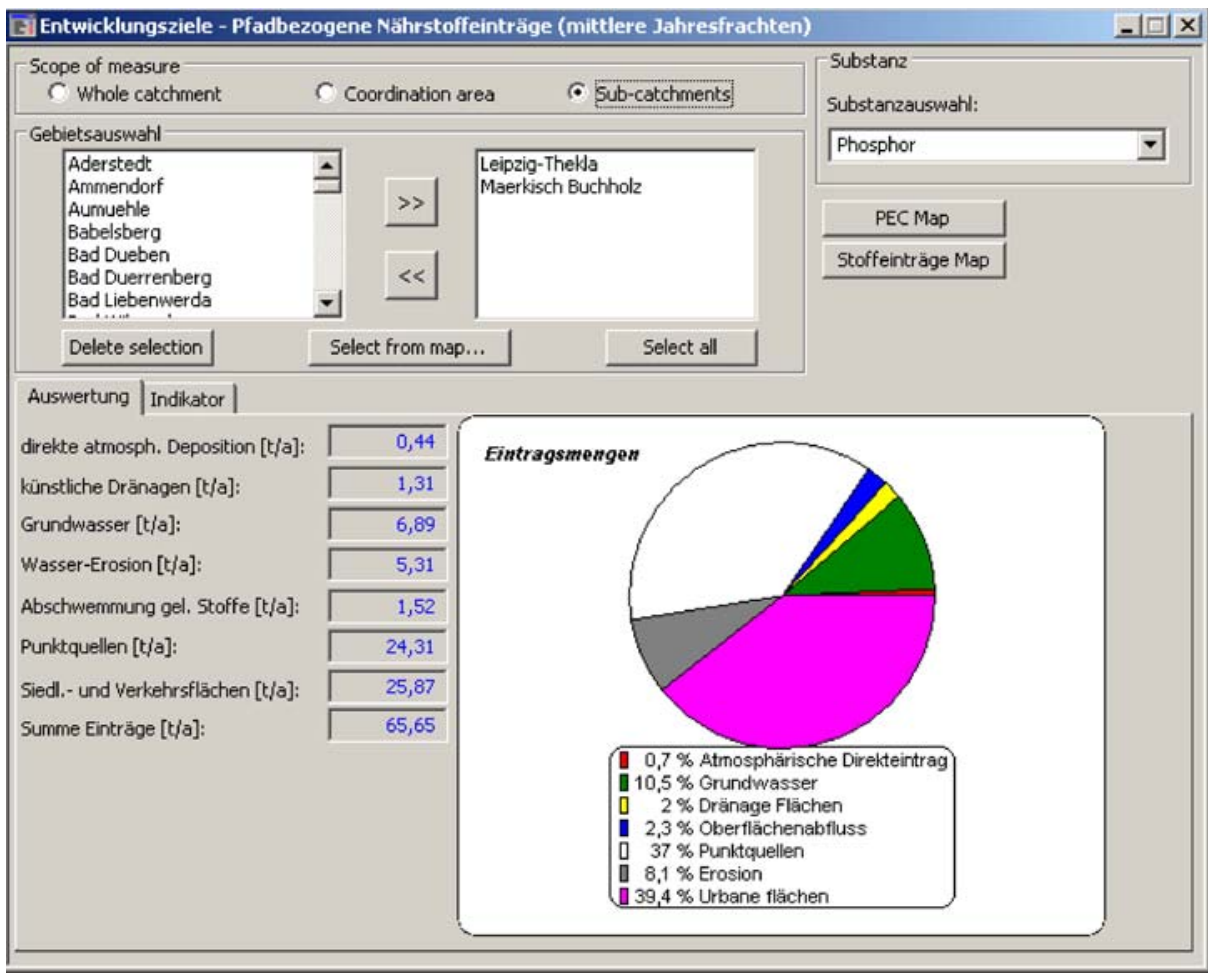

Fig. 5 Average annual loads of phosphorus for a selection of subcatchments. The pie diagram shows the contribution of different pathways such as groundwater, urban areas, and atmospheric deposition 
Fig. 7 Variation of the number of navigable days along the river trajectory for a selected vessel type (depending on selected river measures)

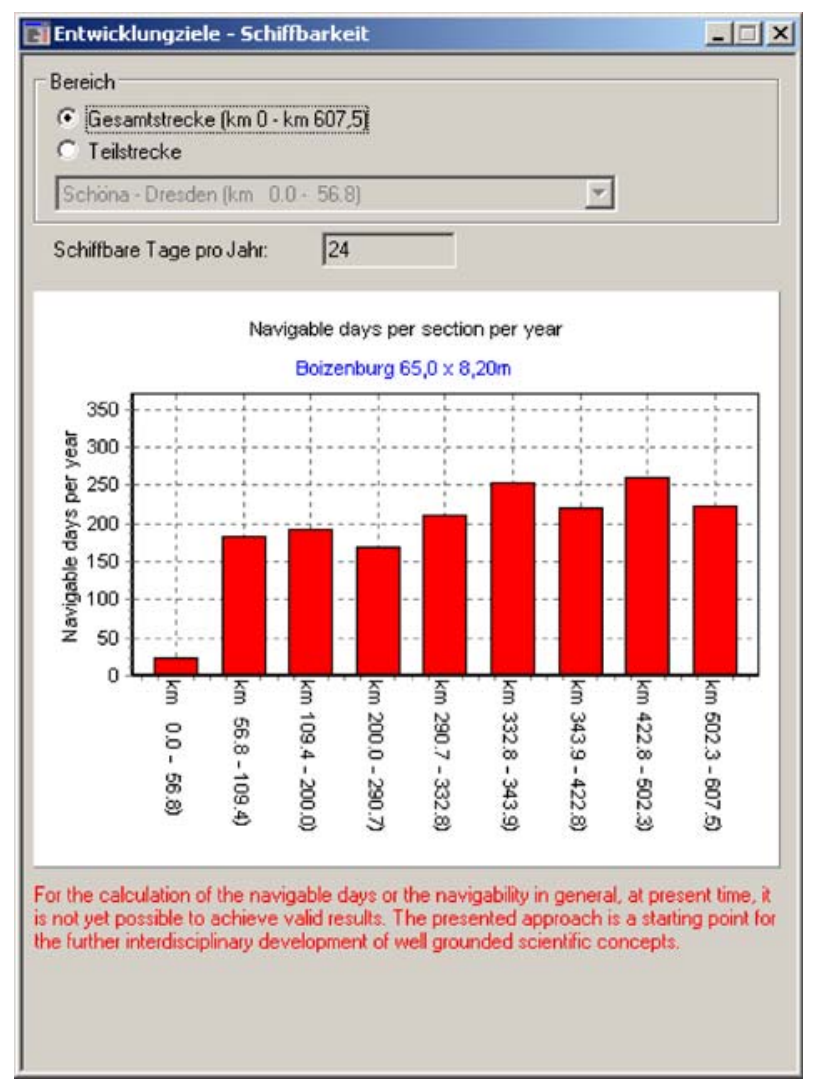

Additionally, the users can select previously computed "external scenarios", such as climate-change scenarios or land-use scenarios. The defined "indicators" are state parameters describing to what extent an objective has been achieved. The external scenarios and the management measures are interrelated and implemented in the system kernel according to the parameters in the models. The ranges within which the user is permitted to vary these parameters are defined on a case-by-case basis in order to avoid meaningless or contradictory settings. Table 2 shows a list of the indicators that have been included in the Elbe-DSS. The indicators were selected by consulting key stake holders and depend in data used in the DSS, their quality

Table 1 Effect of controlled retention on flood risk along the River Elbe for flood events with different return periods without (1) and with (2) retention measures

\begin{tabular}{|c|c|c|c|c|c|c|}
\hline & \multicolumn{2}{|c|}{$\mathrm{T}=10$ year flood } & \multicolumn{2}{|c|}{$\mathrm{T}=100$ year flood } & \multicolumn{2}{|c|}{$\mathrm{T}=200$ year flood } \\
\hline & (1) & (2) & (1) & (2) & $\overline{(1)}$ & (2) \\
\hline Flooded area in $\mathrm{km}^{2}$ & 539 & 538 & 566 & 561 & 686 & 568 \\
\hline Total damage in million $€$ & 116 & 100 & 192 & 168 & 447 & 195 \\
\hline
\end{tabular}

The retention measures comprise 14 polders with a total area of $17 \mathrm{~km}^{2}$ and a summed capacity of 187 million $\mathrm{m}^{3}$ 
Table 2 Implemented management objectives and related indicators for decision making

\begin{tabular}{ll}
\hline Module catchment (ca. $100.000 \mathrm{~km}^{2}$, German part) & Module river network (3rd level) \\
$\begin{array}{l}\Rightarrow \text { Time scale/temporal resolution } \\
\text { Months up to years }\end{array}$ & Months up to years \\
$\Rightarrow$ Spatial resolution & \\
Low, sub-catchments, $100-1000 \mathrm{~km}^{2}$ & ca. 40.000 river stretches of $1-2 \mathrm{~km}$ \\
$\Rightarrow$ Management objectives/decision indicators in the user interface & \\
- Protection of the north sea/amount in & $\bullet$ Improvement of the chemical state \\
reduction of pollutant loads (referring to & of the river network (concentrations \\
pathways, diffuse and point sources, mean & $\mathrm{N}, \mathrm{P}$ and other pollutants per stretch)
\end{tabular}

annual loads $\mathrm{N}, \mathrm{P}$ and other pollutants)

- Cost efficiency of all implemented measures

(e.g. invested $€$ per $\mathrm{kg}$ reduction of P-load)

$\Rightarrow$ Measures/management options

- Land-use changes

- Change in drainage systems

(soil delivery ratio)

- Agricultural practices

- Upstream/downstream migration/connectivity (parameters of weirs and dams)

- Communal waste water treatment

- Reduction of surface sealing

$\Rightarrow$ External scenarios

- Climate change (regionalised precipitationdischarges scenarios), agro-policy, demography

\begin{tabular}{ll}
\hline Module main channel (ca. $500 \mathrm{~km}$ covered) & $\begin{array}{l}\text { Module river section (Elbe-km 400-425, } \\
\text { at Havelberg) }\end{array}$
\end{tabular}

$\Rightarrow$ Time scale/temporal resolution

discharge statistics, partly single events Process oriented, hours up to years

$\Rightarrow$ Spatial resolution

$100 \mathrm{~m}-10 \mathrm{~km}, 1 \mathrm{D}$-model approaches

$10 \mathrm{~m}-50 \mathrm{~m}, 2 \mathrm{D}$ model approaches

$\Rightarrow$ Management objectives/decision indicators in the user interface

- Flood protection/estimation of

flood risks (damage potentials, return periods of flooding)

- Improvement of the ecological status of the floodplain (vegetation/

biotope-distribution)

- Navigability (average days per year)

- Cost efficiency of implemented measures/management options (except river eng. measures)

$\Rightarrow$ Measures/management options

- Dike maintenance/creation of retention areas/polders

- River engineering measures (groynes, dredging, etc.)

- land-use changes

$\Rightarrow$ External scenarios

- Assumption of certain statistically derived flood events (selected return periods)
- Flood protection by estimation of flood risks (damage potentials in $€$, return periods of flooding)

- Improvement of the ecological status of the floodplain (habitat conditions for species (river, riparian and floodplain area)
- Dyke shifting scenarios/variants

- River engineering measures

- Land-use changes (e.g. afforestation in the floodplains)

- Season ( $\rightarrow$ Macrozoobenthos)

- Dyke break scenarios 
and the model parameters. By means of a context sensitive online help ("library function"), all incorporated data and models are documented in terms of authorship and accuracy.

When a set of measures is selected, a simulation with all integrated models can be started. Depending on the settings chosen by the user this may last up to 20 minutes, after which the consequences of an anticipated policy are displayed for the selected indicators. The users can figure out the best "if-then"-scenarios in an iterative way and examine the potential consequences of their recommendations. This knowledge is essential for the development, evaluation, and negotiation of a policy. The application of the Elbe-DSS or similar tools improves the ability for every party to develop particular ideas but also to find commonly agreed compromises. A typical example is the package of maintenance measures to be taken by the WSV for a certain stretch of the Elbe. These are subject to a co-operative procedure since nature protection zones and indicators of the EU-WFD are affected. Another example is the development of a strategy to set up incentives for the agricultural sector to reduce nutrient loads with the highest cost-efficiency. The sub-catchments where a change in farming practices should be supported financially by the public, have to be determined. As required by the EU-WFD a public participation process is organized via internet information systems, brochures and discussions on conferences under the responsibility of NGOs and the Länder. Practice-oriented decision support systems can also contribute to participative processes (Möltgen and Petry 2004; Giupponi et al. 2007). In parallel to the above described application for the development of a policy, the Elbe-DSS approach is also appropriate to be used within a participative process. The agricultural sector is an important stakeholder in the river basin and involved in decisions, but is not a real decision maker in the water management tasks described above. The sector is more or less affected. Here the authors see a future potential for use of the Elbe-DSS. A quantitative or qualitative evaluation or a multi-criteria analysis tool as proposed by e.g. Hostmann et al. (2005), has not been implemented so far. Technically the simulation results of the DSS can be exported in the form of datasets, which can easily be used in such tools.

\section{Software Engineering}

\subsection{State of the Art}

A complete review of the history of software engineering is beyond the scope of this paper, but it is useful to compare the design process of the Elbe DSS with some typical approaches. During the past decades different software engineering approaches were followed to carry out complex design projects such as the development of the Elbe DSS. The approaches differ both in organizational and technical terms, as well as the extent and timing of user involvement. The waterfall model Royce (1970) is a non-iterative process in which the specification of requirements, design, code implementation, integration, testing, and maintenance are sequentially completed. The users are primarily involved in the initial requirements specification phase. The rigidity of completing one step before going to the next makes the waterfall model inflexible to cope with changing user requirements during the project and unexpected problems, two issues that were observed in the Elbe DSS project. Nevertheless, some DSS for IRBM are still developed in this way, albeit unintentionally. The waterfall 
model can be improved by allowing for iterations as proposed by Royce (1970). Software prototyping (Crinnion 1991) provides the users with an outlook on the final product in the form of a prototype design with a limited number of features. Their feedback can then be used during the remainder of the project. A pitfall of prototyping is that facade features may raise false or unrealistic expectations. The Elbe DSS itself was intended to be a prototype for a full features DSS. In addition, prototyping deliverables were used starting half-way the project to facilitate the communication with users and obtain more meaningful feedback. The MULINO project (Giupponi et al. 2004) also relied on prototyping to involve users. The spiral model (Boehm and Belz 1988) is a combination of the waterfall model and software prototyping, using both bottom-up and top-down concepts for the design. During the design of the Elbe DSS the availability models and data drove the design bottom-up on the one hand, whereas the system diagram served as top-down structure to keep the design in focus on the other hand. The rational unified process (Kruchten 2004) is founded on the spiral model and analysis of the failures in earlier projects. It uses the object-oriented Unified Modeling Language (UML). The method is iterative and characterized by adaptation to the user/organizational setting, a continuous emphasis on software quality, balancing of stakeholder priorities, and team collaboration. A good example is the GLOWA Danube project (Ludwig et al. 2003). Aspects of the rational unified process could also be observed in the Elbe DSS project, reflected by the bi-monthly developers meetings, frequent consultations with users and emphasis on direct communication between the software engineers and researchers. Agile software development methods (Cohen et al. 2004) are highly flexible and unplanned, with quick adaptations to changes. A detailed prospect on deliverables can only be given on the short-term, long-term goals are general. Agile development works best with small teams of expert developers. The approach is in contrast with the Elbe project, which was based on detailed planning as much as possible. The German $V$ model (Bröhl and Dröschel 1995) is the standard for software engineering for the German federal government and also widely used in the USA. The V shape (Verification and Validation) depicts the activities of design, implementation, and testing. The aim is to improve the cost-effectiveness by setting the objectives at an early stage, thorough requirement specification, and an emphasis on testing. Each requirement corresponds to a design object. The approach is more rigid than the practice for the Elbe DSS design. In general terms the design process of the Elbe DSS bears characteristics of prototyping and the rational unified process, taking a middle road between highly flexible and highly planned software engineering methods with room for multiple iterations and regular though not continuous consultations with stakeholders and envisaged users.

\subsection{The Elbe DSS}

\subsubsection{General Procedure}

The design of the DSS was based on a systems analysis approach (Miser and Quade 1985; De Kok and Wind 2002) with four distinct stages:

- Problem formulation: identifying key users and stakeholders, relevant problems and objectives; formulating tentative measures and possible boundary conditions; identifying the future economic and physical conditions that may interfere with the measures. 
- Qualitative system design: identifying the relevant social-economic, physical, and ecological variables and processes; cause-effect reasoning to link measures to objectives via the processes in a qualitative system diagram.

- Quantitative system design: collecting models and data needed to design a quantitative framework of analysis based on the qualitative system diagram of the previous step.

- Implementation of the DSS: technical integration of models and data in an interactive DSS with a graphical user interface based on the qualitative system design; verification (debugging) and validation of the DSS functioning.

Obviously, these activities were to take place in an interactive, iterative, and flexible way, to deal with changing user requirements and allow for feedback on the design, as well as unexpected problems. For example, in some cases data and models had to be collected during the project. Nevertheless, the four stages were used to structure the design process at a general level. The qualitative system diagram was regularly updated to monitor the progress of the design. The online help library, which documents all models and data used in the DSS, provides literature references and scientific background information to assist the user with structuring the current knowledge and available data for the Elbe river basin. This activity started about half-way the project with increasing effort towards the end of the project. The main objective of the library is to make the underlying scientific assumptions and concepts transparent, allowing for open discussion of the complete scientific content of the DSS. The application of different scientific concepts for similar functionalities made the DSS design more complex than was originally anticipated. To avoid confusion among the users the online library documentation makes frequent use of hyperlinks to related model concepts and DSS functionalities. In particular this was considered important for researchers and stakeholders who would like to explore functionalities that differed from their own research or management background, or those interested in trans-disciplinary linkages between measures and objectives.

\subsubsection{Model Integration}

For the pilot version of the Elbe-DSS, many of the software components were not developed from scratch; instead they were derived, adapted and extended from generic classes provided by Geonamica ${ }^{\circledR}$, an object-oriented application framework for ISDSS (Hahn and Engelen 2000). The primary benefits of using an application framework for ISDSS development stem from two types of reuse: design reuse and implementation reuse. The observation that core concepts and components and their interactions within the domain of ISDSS are relatively stable, has led to the notion of 'design patterns'. Design patterns can be identified at the architectural level (e.g. interaction between the simulation engine and model building blocks) and at the domain level (e.g. interaction between a dynamic land use model and a transportation model). An application framework supports design reuse, by delivering a useful set of documented software design patterns, as well as implementation reuse, by providing partial solutions in the form of a skeleton application and class libraries. Therefore, using a framework for ISDSS development may save large costs for rediscovery and reinvention. Besides providing economic benefits, such frameworks enhance the 
modularity by encapsulating unstable implementation details behind stable interfaces. The stable interfaces enhance reusability by defining generic components that can be reapplied to create new ISDSS applications. In addition, a generic framework enhances the extensibility by providing 'template methods' that allow applications to extend their stable interfaces with application specific behavior (Fayad et al. 1999).

Model integration is an issue that receives increasing attention, see for example the Open Modeling Interface and Environment (Open MI 2008). In general the methods used for technical model integration can be grouped into three categories: (1) strong coupling, (2) weak coupling and (3) reimplementation (Hahn and Engelen 2000).

Strong coupling means that the model is equipped with a software interface that enables direct exchange of data structures with other software components. This can be achieved by implementing a so called 'wrapper' that provides the required interface. Among the advantages of this method we find that, if at all, only a small part of the original model code has to be adapted and that it is possible to achieve model integration with very low computational overhead. On the downside we find that it can be a non-trivial engineering effort to develop the interface wrapper. For small models, the amount of wrapper code sometimes even exceeds the model code.

With the weak coupling method, the file system or a database is used as an indirect link between the models. In cases where a model is only available as executable software code without a programming interface, this is often the only way to integrate the model. Among the advantages of the weak coupling approach we find that it has very few requirements for the model to be integrated. The source code of the model is not required and it is sufficient to know the exact format of the input/output files or database to control the model. The drawback of the weak coupling method, especially when using the file system for data exchange, is that it often creates a performance bottleneck in the DSS, because disk memory access is several orders of magnitude slower compared to communication via the main memory. This performance bottleneck often becomes critical when individual models are arranged in a dynamic simulation context and frequently need to exchange large spatial data structures (e.g. raster maps), which is very common with spatially explicit models used in an environmental DSS. Recent developments in spatial database technology show improved support for large multidimensional raster data (Reiner et al. 2002; Vinhas et al. 2003), which may lessen the performance-related disadvantages of the weak coupling approach to some degree.

Reimplementation of a model is an approach, which keeps all design options for technical integration open. From a software engineering point of view, reimplementation often produces by far the best results. For small models, reimplementation of the model in the language of the DSS often takes considerable less effort compared to the 'wrapper' approach. However, from an organizational point of view, reimplementation has the disadvantage that it creates a new independent version of the model. In most cases, this version will not replace the original version of the model author and therefore, for the whole lifecycle of the DSS two parallel model versions need to be maintained, updated, synchronized and tested. Reimplementation also means that the software engineer, at least partly, takes over the (scientific) responsibility for the (re-implemented version of the) model from the original author.

Each method for technical model integration has its own specific strengths and weaknesses. In the Elbe-DSS project, the decision about which method to use was 
taken for each model individually on the basis of a thorough model review, which involved technical, scientific and end-user oriented criteria. Close cooperation between scientists and software engineers, as early as possible in the model development process, yields the best results in terms of flexible, robust and well engineered model implementations that can be reused and integrated as components in larger systems such as ISDSS.

\subsubsection{Project Organization and User Involvement}

The multi-disciplinary development team consisted of researchers of several universities, consultants, and software engineers, and was coordinated by the BfG with multiple roles as model deliverer, potential user and intermediary for other users. To guide the project and to ensure a final product with functionalities that matched the requirements of the different users these were involved in the design process on a frequent basis during the whole development process. This was done by selecting a number of representatives of different stakeholders: research institutes and public organizations responsible for nature protection, shipping, flood safety, water quality, and other functions. The project started with the identification of potential end-users during the feasibility study that preceded the project (Van Delden 2000; Verbeek et al. 2000) to discuss relevant problems and potential measures. In many cases the persons that were interviewed represented organizations responsible for a specific river function, such as flood safety or vegetation ecology, and the users did not have a picture in mind of a DSS for integrated river-basin management. At the beginning of the main project a steering committee was formed to monitor the progress and give feedback on the achievement of milestones and the user orientation of the tool. Halfway the project a stage was reached where a tentative functionality of the DSS could be shown to selected stakeholders. Their feedback has been used to adapt and improve the design. In this way the users gradually obtained a clearer picture of what a DSS could look like. With time progressing the comments and suggestions of the users were aimed at the definitive choices of measures and indicators, followed by the detailed aspects of the user interface in the final year of the project. Furthermore, bimonthly project meetings were held, during which the progress could be verified and technical or scientific problems discussed or prevented.

\section{Formulating Models}

Once the problems and solutions had been identified and translated into a qualitative system design models and data were needed to make the desired functionalities possible. The step of collecting data and (re)formulating models based on the functional requirements was less obvious than anticipated as the following two examples will illustrate.

\subsection{Flood Risk Assessment}

For a technical description of the flood risk assessment the reader is referred to the online manual that comes with the Elbe-DSS and earlier publications (http://elise.bafg.de/?7295). Here, the focus lies with the design history of this func- 
tionality. From the beginning onwards, assessing flood safety was a key functionality of the prototype DSS. Several sections of the dikes along the River Elbe required maintenance (IKSE 2004) and dike failure occurred at different places in the recent past, with the flood catastrophe of August 2002 in Middle Europe as unprecedented example. This flood resulted in over nine billion Euro flood damage in Germany alone (IKSE 2004), mostly along the tributaries of the River Elbe, and occurred by the end of the conceptualization phase of the project. Up to that moment the flood risk functionality of the prototype DSS focused on "static" assessment of the flood risk at the aggregated level of the main channel. Only the one-dimensional hydraulic-numerical model HEC-2 was available (USACE 1982; Otte-Witte et al. 2002) to determine the water levels in the main channel as a function of the (peak) discharge. This model was calibrated for discharges with a recurrence interval up to 100 years. The dikes along the river Elbe have a protection level in the range of 10-200 years, excluding a $0.5-1 \mathrm{~m}$ safety board (IKSE 2004). To demonstrate the effect of dike heightening it was decided to use the stage-discharge relationships of the HEC-2 model to calculate the water levels pertaining to peak discharges with a recurrence interval between 10 and 200 years. In case this water level exceeded the dike height, this was considered to result in overtopping of the dike crest. Due to the absence of a validated 2D hydrodynamic model these water levels were extrapolated in the cross direction to determine the inundation depths in case of dike overtopping. Stage-damage functions (De Kok and Huang 2005) for selected, riskrelevant land-use classes were used to determine the corresponding flood damage. For a selected river section south of the town of Havelberg (Elbe km 425) the probabilistic risk was shown in terms of qualitative risk classes, based on the flood damage multiplied with the exceedance probability of the peak discharge in the main channel. This simple approach had several limitations: only the effect of landuse change and dike heightening were included, the downstream propagation of a flood wave could not be included, the maximum inundation depths only roughly represented the effect of dike overtopping and not a dike breach, and the flow velocities in the inundated areas could not be determined. In response to the events that occurred during the 2002 flood and increased attention for discharge-oriented measures from the side of the authorities (IKSE 2004) it was decided to refine the model in two respects. First, the hydraulic model was linked to the one-dimensional flood routing model ELBA (Fröhlich 1998) and a GIS-based approach was included to describe the effect of retention measures on the downstream peak discharges (Helms et al. 2002). Second, local stakeholders were consulted to identify four vulnerable locations. The $2 \mathrm{D}$ hydrodynamic model SOBEK of WL|Delft Hydraulics (http://www.sobek.nl) was used to simulate a dike breach and obtain accurate maps of the maximum inundation depth, flow velocities, and corresponding flood damage. Because it was not technically and budgetary feasible to incorporate the SOBEK model into the DSS only pre-calculated maps were shown. In addition, the strategic purpose of the pilot DSS limited the computational load of the models that could be incorporated. This meant that users could only choose among the four locations, and were not able to examine the consequences of flood events that differ in magnitude or location. The resulting functionality has some advantages as well as drawbacks, both conceptually and in terms of the practical usefulness. The 1D hydraulic approach provides information on the flood risk at the aggregated scale of the German Elbe as a whole. This is useful from the river-basin planning perspective and to analyze flood 
risk mitigation measures with strong non-local effects, such as retention areas. The comprehensive 2D hydrodynamic computations with SOBEK are more accurate, particularly when the dynamic effects of a flood are of concern, but technically less desirable to implement at the river scale. This can be somewhat disappointing for users, who wish to analyze multiple flood prevention measures and flood events for arbitrary locations. Furthermore, the two different approaches make the DSS design less consistent in terms of data and underlying model concepts. In general, the experience with the flood risk functionality of the Elbe-DSS points to three important design issues. First, developers should decide to what extent aggregated and detailed models should be included or not. This design decision should depend on the purpose of the DSS rather than the availability of models and data. Second, the design was science-driven, meaning that the availability of research models and data for selected locations dominate the design, rather than the problems perceived by stakeholders. Third, the application of different location-dependent models makes it very difficult to arrive at a flexible tool that can cope with changes in the model structure and a free choice of measures that can be analyzed by the DSS users.

\subsection{Pollution from Point and Diffuse Sources}

The overall design of the Elbe-DSS and selected models for water quality have been reported by Matthies and Berlekamp (2006). A technical description of the way the selected models have been linked is given in an extra paper (Berlekamp et al. 2007). Because water quality is one of the key issues of the EU Water Framework Directive (EU 2000) it is a key component of the DSS. It was clear that pollution from point and diffuse sources would be of growing importance for the DSS and its end-users. In general water quality modeling follows the downstream path of water soluble pollutants - that means to calculate emissions from diffuse and point sources, describe the transport downstream the river network and take into account the elimination processes in combination with modeled hydrology.

As an outcome of the past fifteen years of intensive research in the Elbe area various models of water and/or nutrient transport exist (Krysanova et al. 1998; Kersebaum and Beblik 2001; Becker et al. 2002) and different hydrological models were already applied to the Elbe catchment (Krysanova et al. 1999; Lahmer et al. 1999; Kunkel and Wendland 2002). An application of the GREAT-ER model (Matthies et al. 2001) to the Elbe catchment was available to model the exposure from point sources and fate of pollutants in the river network. The setup of the water quality functionality of the DSS raised similar design questions as for the flood risk assessment: formulating a model at the appropriate temporal and spatial scale, choosing between a static or dynamic modeling approach, and ensuring flexibility of the model for later changes.

To integrate models adequately into a DSS two scale problems have to be solved. A spatial scale problem occurs because processes at large scales (e.g. the diffuse emissions of nutrients from the whole catchment) have to be linked to smallscale processes (emissions from point sources and fate of pollutants in each river stretch) in a proper way. Because those processes can be described with different models, the adequate modeling scale had to be found. Detailed physically based models for water and/or nutrient transfer such as SWIM (Krysanova et al. 1998) and ARC/EGMO (Becker et al. 2002) combine the vertical and horizontal transport 
of water and/or substances, and are well parameterized and tested for smaller catchments $\left(<1,000 \mathrm{~km}^{2}\right)$ but suboptimal for the application at large scales due to extensive data demands. The simpler but robust budget model such as MONERIS (Behrendt et al. 1999), working on sub-catchments of about $1,000 \mathrm{~km}^{2}$, was already parameterized for the complete Elbe catchment (about $100,000 \mathrm{~km}^{2}$ ) and fitted the intended spatial scale. The MONERIS model was combined with the conceptual rainfall-runoff model HBV-D (Krysanova et al. 1999) that was available for the Elbe catchment but had to be recalibrated for the sub-catchments used in MONERIS. The linking of these two models resulted in a consistent level of aggregation with matching spatial and modeling scales, but raised another problem. Whereas MONERIS and GREAT-ER are static models calculating annual conditions averaged over longterm periods the hydrological model HBV-D is a dynamic model which uses a daily time step. Dynamic simulation of the hydrology is necessary, for example, to describe the effect of time-dependent measures such as retention polders. For GREAT-ER and MONERIS the output of HBV-D is aggregated to mean values.

The integration of the selected models allows the DSS users to simulate the effects of different management options (measures) as well as external scenarios (e.g. climate change or demographic prognosis) on the water quality of the river system. Although a general procedure was available to identify relevant measures in close communication with potential users (see Section 6) it was not meaningful to implement all possible alternatives in all detail. End-user consultations resulted

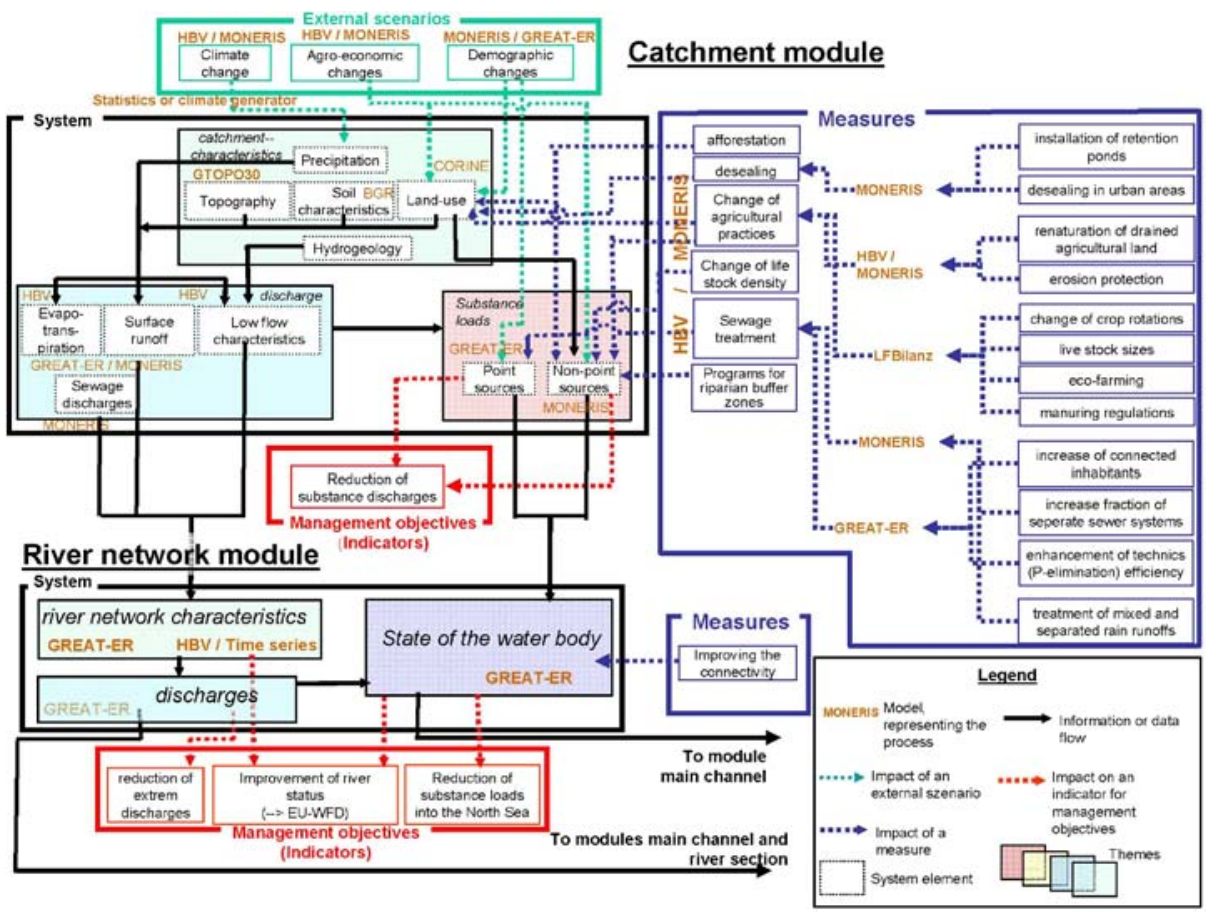

Fig. 8 Linkage of measures and related models in the modules catchment and river network of the final DSS prototype 
in a set of required measures that can be grouped into the following categories: (1) measures related to agro-practice, (2) measures related to changes in land use and (3) measures related to urban sewage treatment. This end-user wish list had to be reduced due to model restrictions-only those measures that are fully supported by the models were implemented in the DSS. A more detailed view on the structure of the catchment and river network modules is shown in Fig. 8.

The advantages of the final water quality functionality consist of a broad set of implemented measures based on user demands, the easy-to-use user interface for selecting those measures and the possibility to evaluate the effects of combined measures and external scenarios (Matthies and Berlekamp 2006; Berlekamp et al. 2007). On the other hand the model integration concept and the selected models themselves resulted in a decreased level of detail and increased uncertainty of the model output. Consultations of users during the project and preliminary tests of the prototype with users pointed out that communicating systems uncertainty will be one of the main challenges for the further development of the water quality functionality and the Elbe DSS in general.

\section{Discussion}

\subsection{Balancing the Design}

The experiences with the Elbe-DSS pilot study and problems mentioned in the literature (Ubbels and Verhallen 2000; Walker 2002; De Kok and Wind 2003; Uran and Janssen 2003; Mysiak et al. 2005; Janssen et al. 2006; Borowski and Hare 2007; Brugnach et al. 2007; Olsson and Andersson 2007) point to communication problems that arise, among other reasons, due to the different backgrounds of the persons who have to cooperate in a DSS project. The users, who are often not clearly known at the beginning, are often represented by a few selected persons from stakeholder organizations. Their principal role is to define the problem and management objectives (Miser and Quade 1985), and give feedback on mainly the qualitative design. The domain experts can be scientists or field experts, who contribute the data and models needed for the quantitative design, and have to validate the DSS at several stages of completion. Software engineers design the user interface and have the difficult task to implement and technically integrate the models and data provided by the domain experts. The design has to be coordinated scientifically by one or more systems architects, who often have a generalist or less critical research background, and organizationally by project managers. In practice persons can have several tasks simultaneously or share their task with others. Many difficulties are reported with the exchange of contributions between developers (Walker 2002; De Kok and Wind 2003; Schielen and Gijsbers 2003). For example, when researchers provide the software engineers with models that are poorly designed from a software engineering point of view (Walker 2002), or come up with last-minute changes of the system architecture that endanger the project planning at a critical stage. Ideally the design of a DSS is an iterative process which focuses towards an optimal balance between quality of the software design, scientific soundness, and the functionality for the users (Fig. 9). 


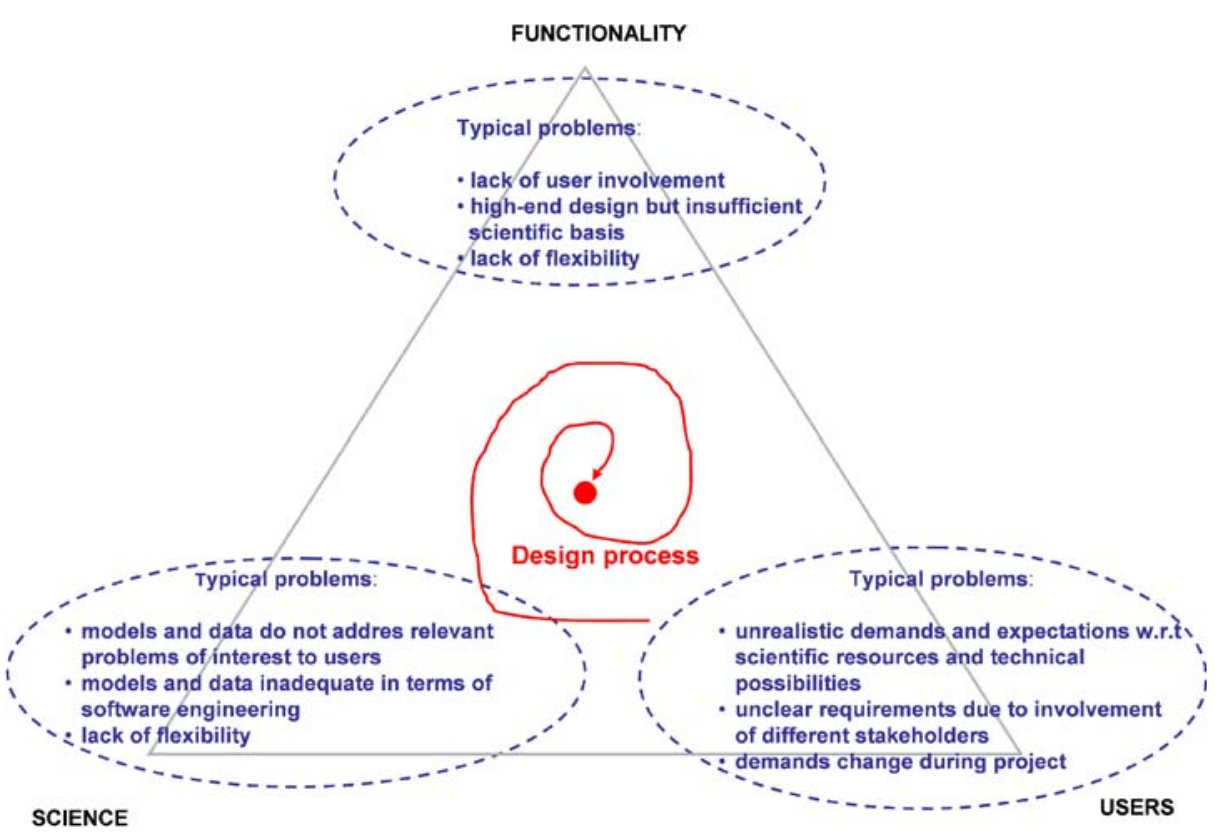

Fig. 9 Iterative design of a DSS with typical problems that arise if one of the aspects of the design is overemphasized, after Calewaert et al. (2007)

If one of these three aspects is overemphasized or neglected problems will occur during the design and implementation phase (see Fig. 9) and the acceptance of the DSS by users will decrease. A review of the problems related to DSS design and use is already available (Walker 2002) and the literature on project management is vast. Three critical aspects for DSS development and DSS acceptance will be discussed in the following sections, namely communication, internal system consistency, and flexibility. The importance of sound software engineering, both in terms of quality and efficiency, is discussed as well. This is an overarching design aspect linking to the other three aspects, and is often underestimated (Walker 2002).

\subsection{Communication}

Effective communication with potential users throughout the project is essential to ensure that the relevant problems and feasible solutions are addressed by the DSS. The feasibility study that preceded the Elbe-DSS pilot version (Van Delden 2000; Verbeek et al. 2000) was aimed at identifying the potential users of the DSS. This turned out to be difficult for several reasons. First, the project was a researchdriven incentive, instead of a response to existing demands for information from river managers. Second, it was not clear to the persons interviewed what a DSS could mean for their work. Most river managers did not (yet) have experience with the application of a DSS such as the Elbe-DSS prototype in their organization. Third, most interviewed persons had a sectoral background with a focus on a single river function such as nature or flood safety, rather than experience with integrated river management, although they were familiar with the concept. This meant that 
problems and measures could only be discussed at a general level. The decision was therefore made to start the project with a tentative set of generally recognized problems and planned measures, and present a qualitative system diagram as a blueprint for the DSS after one year. The qualitative system diagram (Fig. 3) proved to be very useful to communicate the design and to structure discussions within the DSS development team and with the domain experts and stakeholder representatives. The system diagram was updated regularly and served three important purposes: to present as clearly and user-friendly as possible an overview of the actual status of the design including processes and variables, measures, scenarios, management objectives, and the models that were used (De Kok and Wind 2002), to facilitate the discussions between the designers and scientists on the one hand and the designers and selected users on the other hand, and to provide a gradually focusing layout for the DSS and user interface for the software engineers. Due to changes in the functionality and priorities of the users the design of the system diagram was a continuous activity although most of the effort was made during the first half of the project. With ongoing changes to the design absolute perfection of the system diagram was not the goal. After several iterations the system diagram was considered to be consistent and only limited changes were implemented because adaptations become more difficult towards the final stage of the project in view of the consistency with other models and the user interface.

\subsection{Internal Consistency}

Most DSS developments in environmental issues, the Elbe-DSS included, are science-driven rather than user-driven, which means that the design is based on models and data addressing specific scientific problems, instead of real-world issues from a potential users' perspective. In principle such a bottom-up approach is not a problem, provided that the models and data pertain to the issues that are brought up by the users. In the case of the Elbe-DSS the most relevant models and data were identified after the problem formulation with the users (Verbeek et al. 2000), in order to decide whether the design was feasible. Research models usually require more accurate and expensive data, and have a scientific, discipline-oriented purpose rather than being a part of an integrated software tool. Furthermore, these models are sometimes more complex than necessary for the intended use in a DSS, and limited to specific research locations. Therefore, the application to other measures or scenarios without collecting new data or recalibration can be difficult. As was discussed in Section 5 the application of research models in a DSS poses a scientific challenge related to the integration with models with different types and quality of input. It is not meaningful to use the output of an accurate model as input for a coarse model. The aim of appropriate modeling (Xu and Mynett 2006; De Kort and Booij 2007) is to ensure the DSS design matches the user requirements. Such a DSS has a high degree of internal consistency (De Kok and Wind 2002, 2003). Much attention was paid to the consistency of models and data, for example to determine the appropriate spatial resolution of the elevation grid in the floodplains. For example, the appropriate vertical accuracy of the elevation data for the floodplains could be derived from the sensitivity of the ecological model that used the elevation data as input (De Kok and Holzhauer 2004) and turned out to be $0.5 \mathrm{~m}$ approximately, thus matching the quality of the elevation data (BKG 2003). The horizontal resolution of the elevation 
data was $20 \times 20 \mathrm{~m}$. Based on the river-scale application of the ecological model and integration with the CORINE land-use data (EEA 2002), with a $100 \times 100 \mathrm{~m}$ resolution, it was decided to aggregate the elevation data to this spatial resolution.

\subsection{Flexibility}

Both the users and their requirements will often change during a long-term project, particularly when data and models are partially under development. At several stages during the project iterations between the three design activities (problem formulation, qualitative design and quantitative design) were allowed for, and also proved to be necessary. As mentioned before, the August 2002 flood called for extension of the channel module with retention polders, which affected not only the qualitative system diagram and model base, but also the user interface and underlying technical design and implementation. At later stages of a project such changes become more and more difficult to implement, both for organizational and technical reasons. Complex models can answer specific questions more accurately but at the cost of a larger computational load. Although the direct integration of a model has the advantage that the functionality becomes fully available to users, the computational load can become too large for interactive use in, for example, sessions with stakeholders. For this reason the dike break simulations that were computed with SOBEK have been incorporated in the DSS as precalculated scenarios. This limits the choice to a limited number of locations, but in this case this was not considered to be a problem because these had been proposed by the users themselves. Simple models are more flexible and easier to replace or generalize to new locations because the data collection and model setup are generally less demanding. The general lesson is that, particularly in the beginning of the design, DSS developers should attempt to keep their models as simple as possible. If necessary, complex models can be replaced by simpler replica models that capture the essential behavior of the original model. Future research should focus on improving the scientific quality of such simplified models. Furthermore, interpolation of model results can be used to complete data gaps or determine the consequences of alternatives that have not been precalculated. The latter approach, for example, is used in the user-friendly Planning Kit for river management (Van Schijndel 2005).

\subsection{Software Engineering}

The developers of an integrated spatial decision support system (ISDSS) are usually well aware of the importance of end-user involvement but often underestimate the complexity of the software engineering aspects of their project (Walker 2002). Two aspects of software engineering for ISDSS development require more elaboration: (1) object-oriented application frameworks and (2) technical model integration.

The experience of the Elbe-DSS project is that few research models meet the quality standards of modern software engineering. In almost all cases the models that are to be integrated in a DSS are not designed to be part of a complex software system in the first place. When integrating existing models and data from previous research projects the DSS software engineer must be prepared to deal with: (1) various programming languages, (2) various compilers and interpreters, (3) various 
runtime environments (4) various operating systems, (5) various concepts for data and memory management, (6) open and closed systems and (7) too many ad-hoc data formats. Furthermore, existing models almost never feature a software interface that enables them to be controlled by another software component (e.g. a simulation engine). As long as such models are used in a research environment, in contrast to being part of a larger system targeted at end-users, this often is not perceived as a problem. However, to create a usable ISDSS, the software engineer has to technically integrate data and models according to the design blueprinted in the conceptual system diagram. To achieve this, each individual model is wrapped with a standardized software interface that enables the model to function as a component in a network of coupled models (Zeigler et al. 2000). Next, the network of coupled models is put under the control of a simulation engine, which acquires the information about the input/output dependencies of all individual model components. This is necessary to ensure their execution in the correct order. Furthermore, software components have to be designed that interactively process the user input for measures and scenarios and feed it to the models, as well as components that take the output of the models and present it in a way that is meaningful for the user. Last but not least, the integrated model requires an interface with many sources of spatial and non-spatial data in various formats.

\section{Conclusions}

The problems encountered during the design of a DSS and lack of institutional implementation by potential users have lead to skepticism with respect to the usefulness of these tools. According to Walker (2002) DSS should be considered as learning tools, rather than instruments to support the decision-making process, although the two purposes are interrelated. Many of the problems reported in the literature can be overcome, or at least mitigated, by paying attention to the following aspects of DSS development and DSS application:

Motivation and purpose of the DSS. Different functions are attributed to decisionsupport systems in environmental management ranging from a learning tool, library system, discussion instrument to analysis of decision problems. Whether a DSS is appropriate and which functions are more relevant should be decided by the developers and users prior to or at the beginning of the project.

Communication. The roles of software engineers, analysts, users, and domain experts in a DSS development team (see Fig. 9) call for effective communication from the start, and a proper balance between the scientific content of a DSS, flexibility for the users, and sound software engineering principles. A regularly updated qualitative system diagram, which includes the measures, indicators, scenarios, and key processes, facilitates the discussions within the DSS development team, as well as with stakeholders and users.

Appropriate modeling. Many DSS projects still follow a bottom-up, science-driven design path by taking scientific research and model availability as starting points, rather than a demand from potential users. The availability of models and data does not guarantee their applicability in a DSS. Preferably, the selection of models and data should be based on internal system consistency, supported by a-priori sensitivity 
and uncertainty analyses. This approach can be referred to by the term 'appropriate modeling' (see Section 6.3).

Flexibility. In principle models should be kept as simple as possible to analyze the problems at hand, in order to maintain a certain degree of flexibility for future changes of the DSS design. If necessary, complex research models can be incorporated as simpler replica or meta models. Formulating such meta models is not a straightforward matter, and poses a challenge requiring close cooperation of domain experts and system architects. In this respect it may be helpful to support the modeling process by means of sensitivity testing of sets of coupled models. A lack of flexibility to cope with changing priorities or different demands with regard to the functionality may endanger its acceptance among a wider audience, once a DSS is completed. The experience with the Elbe-DSS demonstrates that a DSS is not a static instrument, but requires continuous adaptation to keep up with scientific progress, changing societal priorities, and physical conditions due to e.g. climate change.

Follow-up and institutional implementation. Project budgets should allow for maintenance of the DSS and keep users involved in its further development. To this aim key stakeholders with a view on the possibilities of the DSS should be integrated as project partners with a certain budget and own responsibility for e.g. data delivery and a role in the design of the user interface. An implementation plan, albeit tentative, should be formulated at an early stage of the design, so that users and developers have a reasonable picture of the intended use of the DSS. Last but not least, successful DSS development should be seen like a normal product development cycle, consisting of development, testing and marketing. Most of the DSS developments in IRBM until now are financed by research budgets that end at the first step of this cycle. To finalize the product and turn potential users to real users an intensive testing phase, in which the users are involved, should be followed by a sound implementation strategy.

Acknowledgements This research has been funded by the German Ministry of Education and Science (BMBF) in the framework of project "Elbe-Ecology, Phase III: Combination of results of the Research Association Elbe-Ecology ", FKZ 0339542A.

Open Access This article is distributed under the terms of the Creative Commons Attribution Noncommercial License which permits any noncommercial use, distribution, and reproduction in any medium, provided the original author(s) and source are credited.

\section{References}

Barrow CJ (1998) River basin development planning and management: a critical review. World Dev 26(1):171-186. doi:10.1016/s0305750X(97)100171

Becker A, Klöcking B, Lahmer W, Pfützner B (2002) The hydrological modelling system ARC/EGMO. In: Singh VP, Frevert DK (eds) Mathematical models of watershed hydrology. Water Resources, Littleton/Colorado, pp 321-384

Behrendt H, Huber P, Opitz D, Schmoll O, Schmoll R, Uebe R (1999) Nährstoffbilanzierung der Flussgebiete Deutschlands (Nutrient balances of the German catchments), UBA-Texte 75/99, Berlin (in German)

Berlekamp J, Boer S, Graf N, Hahn B, Holzhauer H, Huang Y et al (2005) Aufbau eines PilotDecision Support Systems (DSS) zum Flusseinzugsgebietsmanagement am Beispiel der Elbe. Abschlussbericht (Design of a pilot decision-support system for river-basin management with the 
Elbe river as example—Final report), Mitteilung Nr. 10 Projektgruppe Elbe-Ökologie. Federal Institute of Hydrology, Koblenz, Germany. http://elise.bafg.de/?3283

Berlekamp J, Lautenbach S, Graf N, Reimer S, Matthies M (2007) Integration of MONERIS and GREAT-ER in the decision-support system for the Elbe river basin. Environ Model Softw 22(2):239-247. doi:10.1016/j.envsoft.2005.07.021

BKG (2003) Bundesamt für Kartographie und Geodäsie (BKG) Digitales Geländemodell 1:25.000 des Elbegebietes-Digital terrain model 1:25.000 of the Elbe river basin, on CD-ROM.-ATKIS* DGM25-D-V, Federal Agency for Cartography and Geodesy, Modified by the Federal Institute of Hydrology, Frankfurt. http://www.bkg.bund.de

Boehm BW, Belz FC (1988) A spiral model of software development and enhancement. IEEE Computer 21(5):61-72

Borowski I, Hare M (2007) Exploring the gap between water managers and researchers: difficulties of model-based tools to support practical water management. Water Resour Manage 21:10491074. doi:10.1007/s112690069098

Bröhl AP, Dröschel W (1995) Das V Modell (The V Model), 2nd edn. Oldenbourg, München-Wien. (in German)

Brugnach M, Tagg A, Keil F, De Lange W (2007) Uncertainty matters: computer models at the science-policy interface. Water Resour Manage 21:1075-1090. doi:10.1007/s112690069099

Calewaert JB, Maes F, Lymberry G, Engelen G, Van Lancker V, Vanaverbeke J et al (2007) Chapter 7: conclusions and recommendations. In: Calewaert JB, Maes F (eds) Science and sustainable management of the north sea: Belgian case studies. Academic, Gent, Belgium, pp 251-305

Castelletti A, Soncini-Sessa R (2007) Integrated planning procedure for decision making in water resource systems. In: Castelletti A, Soncini-Sessa R (eds) Topics on system analysis and integrated water resource management. Elsevier, pp 3-23

Castelletti A, Cellina F, Soncini-Sessa R, Weber E (2007) Comprehensive testing and application of the PIP procedure: the Verbano project case study. In: Castelletti A, Soncini-Sessa R (eds) Topics on system analysis and integrated water resource management. Elsevier, pp 223-241

Cohen D, Lindvall M, Costa P (2004) An introduction to agile methods. In: Advances in computers. Elsevier, New York, pp 1-66

Crinnion J (1991) Evolutionary systems development, a practical guide to use of prototyping within a structured systems methodology. Plenum

De Kok JL, Booij MJ (2008) Deterministic-statistical model coupling in a DSS for river-basin management, Environ Model Assess (available online). doi:10.1007/s1066600891617

De Kok JL, Holzhauer H (2004) Pitfalls and challenges in the design and application of decision support systems for integrated river-basin management. In: Möltgen J, Petri D (eds) Interdisziplinäre Methoden des Flussgebiets-managements, Münster, IFGI Prints 21. Institut für Geoinformatik, Münster, Germany, pp 97-104, 15-16 March 20

De Kok JL, Huang Y (2005) Assessment of flood risk at various scales: the Elbe prototype DSS. In: Van Alphen J, Van Beek E, Taal M (eds) Third international symposium on flood defence, Nijmegen, Floods, from defence to management. Symposium papers. Balkema, Leiden, pp 129135, 25-27 May 2005

De Kok JL, Wind HG (2002) Rapid assessment of water systems based on internal consistency. J Water Res Pl-ASCE 128(4):240-247. doi:10.1061/(ASCE)0733-9496(2002)128:4(240)

De Kok JL, Wind HG (2003) Design and application of decision-support systems for integrated water management: lessons to be learnt. Phys Chem Earth Pt B 28(14-15):571-578. doi:10.1016/S1474-7065(03)00103-7

De Kort IAT, Booij MJ (2007) Decision making under uncertainty in a decision support system for the Red River. Environ Model Softw 22(2):128-136. doi:10.1016/j.envsoft.2005.07.014

De Leeuw ACJ (1974) Systeemleer en organisatiekunde: een onderzoek naar de mogelijke bijdragen van de systeemleer tot een integrale organisatiekunde (Systems-and organizational science: an investigation of the potential contributions of systems science to an integrated organizational science). Stenfert-Kroese, Leiden, The Netherlands (in Dutch)

Dietrich J, Schumann AH, Lotov AV (2007) Workflow orient. Participatory decision support for integrated river basin planning. In: Castelletti A, Soncini-Sessa R (eds) Topics on system analysis and integrated water resource management. Elsevier, pp 207-221

Downs PW, Gregory KJ, Brookes A (1991) How integrated is river basin management? Environ Manage 15(3):299-309. doi:10.1007/BF02393876

EEA (2002) European Environment Agency, CORINE Land cover database. Retrieved http:// dataservice.eea.eu.int/dataservice 
EU (1992) Council Directive 92/43/EEC of 21 May 1992 on the conservation of natural habitats and of wild fauna and flora. http:/ec.europa.eu/environment/nature/legislation/ habitatsdirective/index_en.htm

EU (2000) Directive 2000/60/EC of the European parliament and of the council of 23 October 2000. Establishing a framework for community action in the field of water policy. Official Journal of the European Communities L327, 1-72. http://europa.eu.int/comm/environment/ water/water-framework/index_en.html

Fayad ME, Schmidt DC, Johnson RE (1999) Building application frameworks: object-oriented foundations of framework design. Wiley

Fröhlich W (1998) Auswertung der mit dem ELBA-Programsystem berechneten Wasserstandsvorhersagen vom Zeitraum August 1995 bis Dezember 1997 (Evaluation of the water level predictions calculated with the ELBA program system for the period August 1995-December 1997), German Federal Institute of Hydrology, Koblenz, Berlin

Giupponi C (2007) Decision-support systems for implementing the European water framework directive: the MULINO approach. Environ Model Softw 22:248-258. doi:10.1016/ j.envsoft.2005.07.024

Giupponi C, Mysiak J, Fassio A, Cogan V (2004) MULINO-DSS: a computer tool for sustainable use of water resources at the catchment scale. Math Comput Simul 64:13-24. doi:10.1016/ j.matcom.2003.07.003

Giupponi C, Mysiak J, Depietri Y, Tamaro M (2007) Harmoni-CA synthesis report. Decision support systems for water resources management: current state and guidelines for tool development IWA London, UK

Gourbesville P (2008) Integrated river basin management, ICT and DSS: challenges and needs. Phys Chem Earth 33:312-321. doi:10.1016/j./pce.2008.02.007

Gruber B, Kofalk S (2001) The Elbe-Contribution of the IKSE and of several research programmes to the protection of an unique riverscape. Permanent International Association of Navigation Congresses (PIANC) Bulletin No. 106:35-47. http://elise.bafg.de/?3535

HAD (2000) Hydrologischer Atlas von Deutschland (Hydrological Atlas of Germany), Federal Ministry of the Environment, Nature Conservation and Nuclear Safety (ed), 2nd edn. Berlin, Germany. http://had.bafg.de: 8080

Hahn B, Engelen G (2000) Concepts of DSS systems. In: Decision Support Systems (DSS) for river basin management, International workshop 6 April 2000. Federal Institute of Hydrology, Koblenz-Berlin, pp 9-44

Hattermann FF, Gömann H, Conradt T, Kaltofen M, Kreins P, Wechsung F (2007) Impacts of global change on water-related sectors and society in a trans-boundary central European river basin. Part 1: project framework and impacts on agriculture. In: Lindenschmidt KE (ed) Largescale hydrological modelling and the European Union water policies. Advances in Geosciences 11:85-92. http://www.adv-geosci.net/11/85/2007/

Helms M, Büchele B, Merkel U, Ihringer J (2002) Statistical analysis of the flood situation and assessment of the impact of diking measures along the Elbe (Labe) river. J Hydrol (Amst) 267(1-2):94-114. doi:10.1016/S0022-1694(02)00143-9

Henrichsmeier W, Cypris C, Löhe W, Meudt M, Sander R, Von Sothen F et al (1996) Entwicklung eines gesamtdeutches Agrarsektorenmodells RAUMIS 96 (Development of a German agricultural sector model RAUMIS 96), Final document of a cooperation project, Bonn/BraunschweigVölkenrode (in German)

Hoekstra AY (2005) Generalisme als specialisme: Waterbeheer in de context van duurzame ontwikkeling, globalisering, onzekerheden en risico's (Generalism as specialism: Water management in the context of sustainable development, globalization, uncertainties and risks). Inaugural address, University of Twente, Enschede, The Netherlands. http://www.wem.ctw.utwente.nl/ organisatie//Medewerkers/medewerkers/hoekstra/Oratie\%20Hoekstra

Hostmann M, Borsuk M, Reichert P, Truffer B (2005) Stakeholder values in decision support for river rehabilitations. In: Buijse AD, Klijn F, Leuven RSEW, Middelkoop H, Schiemer F, Thorp JH, Wolfert HP (eds) Rehabilitating large regulated rivers Lowland River Rehabilitation Conference, Wageningen, September 29-October 3, 2003. Archiv für Hydrobiologie (Fundamentals of Applied Limnology) 155(1-4). Suppl Large Rivers 15. Schweizerbart, Stuttgart, pp 491-505

IKSE (2004) Aktionsplan Hochwasserschutz (Actionplan for flood protection). International Committee for Protection of the Elbe River (IKSE), Magdeburg, Germany

Janssen MA, Goossen H, Omtzigt N (2006) A simple mediation and negotiation support tool for water management in the Netherlands. Landsc Urban Plan 78:71-84. doi:10.1016/ j.landurbplan.2005.05.005 
Kersebaum KC, Beblik AJ (2001) Performance of a nitrogen dynamics model applied to evaluate agricultural management practices. In: Shaffer M, Ma L, Hansen S (eds) Modeling carbon and nitrogen dynamics for soil management. Lewis, Boca Raton, pp 549-569

Kruchten P (2004) The rational unified process: an introduction. Addison-Wesley object-technology series, 3rd edn. Addison-Wesley, Boston

Krysanova V, Müller-Wohlfeil DI, Becker A (1998) Development and test of a spatially distributed hydrological/water quality model for mesoscale watersheds. Ecol Modell 106(2-3):261-289. doi:10.1016/S0304-3800(97)00204-4

Krysanova V, Bronstert A, Müller-Wohlfeil DI (1999) Modelling river discharge for large drainage basins: from lumped to distributed approach. Hydrol Sci J 44(2):313-331

Kunkel R, Wendland F (2002) The GROWA98 model for water balance analysis in large river basins-the river Elbe case study. J Hydrol (Amst) 259:152-162. doi:10.1016/S0022-1694(01)00579-0

Lahmer W, Becker A, Müller-Wohlfeil DI, Pfützner B (1999) A GIS-based approach for regional hydrological modelling. In: Diekkrüger B, Kirkby MJ, Schröder U (eds) Regionalization in Hydrology. International Association of Hydrological Sciences (IAHS) publication no. 254, pp 33-43

Legris P, Ingham J, Collerette P (2003) Why do people use information technology? A critical review of the technology acceptance model. Inf Manage 40:191-204. doi:10.1016/S0378-7206(01)00143-4

Loucks DP (1995) Developing and implementing a decision-support system: a critique and a challenge. Water Resour Bull 31(4):571-582

Ludwig R, Mauers W, Niemeyer S, Colgran A, Stolz R, Escher-Vetter H et al (2003) Webbased modelling of energy, water and matter fluxes to support decision making in mesoscale catchments-the integrative perspective of GLOWA-Danube. Phys Chem Earth 28:621-634. http://www.glowa.org

Matthies M, Berlekamp J (2006) System analysis for water quality management for the Elbe river basin. Environ Model Softw 21(9):1309-1318. doi:10.1016/j.envsoft.2005.04.026

Matthies M, Berlekamp J, Koormann F, Wagner JO (2001) Georeferenced regional simulation and aquatic exposure assessment. Water Sci Technol 43(7):231-238

Maurel P, Craps M, Cernesson F, Raymond R, Valkering P, Ferrand N (2007) Concepts and methods for analysing the role of Information and Communication tools (IC-tools) in social learning processes for river basin management. Environ Model Softw 22(5):630-639. doi:10.1016/j.envsoft.2005.12.016

Miser HJ, Quade ES (1985) Handbook of systems analysis: overview of uses, procedures, and applications, and practice. Wiley, Chichester

Möltgen J, Petry D (eds) (2004) Interdisziplinäre Methoden des Flussgebietsmanagements (Interdisciplinary Methods of River Basin Management). Schriftenreihe des Instituts für Geoinformatik der Westfälischen Wilhelms-Universität Münster, Workshopbeiträge 15.-16. März 2004, Band 21, S. 1-10, Münster, Germany

Morton MSS (1971) Management decision systems: computer-based support for decision making. Harvard Business School Publishing, Boston

Moss T (2004) The governance of land use in river basins: prospects for overcoming problems of institutional interplay with the EU water framework directive. Land Use Policy 21:85-94. doi:10.1016/j.landusepol.2003.10.001

Mysiak J, Giupponi C, Rosato P (2005) Towards the development of a decision support system for water resource management. Environ Model Softw 20:203-214. doi:10.1016/j.envsoft.2003.12.019

Olsson JA, Andersson L (2007) Possibilities and problems with the use of models as a communication tool in water resource management. Water Resour Manage 21:97-110. doi:10.1007/s11269-006-9043-1

Open MI (2008) http://www.openmi.org

Otte-Witte K, Adam K, Meon G, Rathke K (2002) Hydraulisch-morphologische Charakteristika entlang der Elbe (Hydraulic-morphological characteristics along the Elbe river. In: Nestmann F, Büchele B (eds) Morphodynamik der Elbe, Endbericht des Verbundprojekts (Morphodynamics of the Elbe river-final project report). Institute of Water Resources Management, University of Karlsruhe, Karlsruhe, Germany, pp 203-299

Refsgaard JC, Henriksen HJ, Harrar WG, Scholten H, Kassahun A (2005) Quality assurance in model based water management-review of existing practice and outline of new approaches. Environ Model Softw 20:1201-1215. doi:10.1016/j.envsoft.2004.07.006

Reiner B, Hahn K, Höfling G (2002) Hierarchical storage support and management for largescale multidimensional array database management systems. In: Hameurlain A, Cicchetti R, 
Traunmüller R (eds) DEXA: 13th international work-shop on database and expert systems applications, Aix-en-Provence, 2-6 Sep-tember 2002. Lecture notes in computer science, vol 2453. Springer, London, pp 689-700

Royce W (1970) Managing the development of large software systems, Proc. IEEE WESCON 26, 1-9. http://www.cs.umd.edu/class/spring2003/cmsc838p/Process/waterfall.pdf

Schielen RMJ, Gijsbers PJA (2003) DSS-large rivers: developing a DSS under changing societal requirements. Phys Chem Earth Pt B 28(14-15):635-645. doi:10.1016/S1474-7065(03)00109-8

Scholten M, Anlauf A, Büchele B, Faulhaber P, Henle K, Kofalk S et al (2005) The river Elbe in Germany_present state, conflicting goals, and perspectives of rehabilitation. In: Buijse AD, Klijn F, Leuven RSEW, Middelkoop H, Schiemer F, Thorp JH, Wolfert HP (eds) Rehabilitating large regulated rivers Lowland River Rehabilitation Conference, Wageningen, September 29October 3, 2003. Archiv für Hydrobiologie (Funda-mentals of Applied Limnology) 155(1-4). Suppl Large Rivers 15. E Schweizerbart Science Publishers, Stuttgart, pp 579-602

Scholten H, Kassahun A, Refsgaard JC, Kargas T, Gavardinas C, Beulens A (2007) A methodology to support multidisciplinary model-based water management. Environ Modell Softw 22:743-759. doi:10.1016/j.envsoft.2005.12.025. http://HarmoniQua.org

Scrase JI, Sheate WR (2002) Integration and integrated approaches for assessment: what do they mean for the environment? J Environ Plann 4:275, 294

Sprague RH, Carlson ED (1982) Building effective decision support systems. Prentice Hall, Englewood Cliffs, New Jersey

Ubbels A, Verhallen AJM (2000) Suitability of decision support tools for collaborative planning processes in water resources management. RIZA report 99.067. Institute for Inland Water Management and Waste Water Treatment, Wageningen, The Netherlands. http://www. rijkswaterstaat.nl/rws/riza/home/publicaties/

Uran O, Janssen R (2003) Why are spatial decision-support systems not used? Some experiences from the Netherlands. Comput Environ Urban 27:511-625. doi:10.1016/S0198-9715(02)00064-9

USACE (1982) HEC-2: water surface profiles, user's manual. CPD2A, Hydrologic Engineering Center, U.S. Army Corps of Engineers, Davis, CA

Van Delden H (2000) A generic approach for the design of decision support systems for river basin management, MSc thesis. University of Twente, Enschede, The Netherlands

Van Schijndel SAH (2005) The planning kit, a decision making tool for the Rhine branches. In: Van Alphen J, Van Beek E, Taal M (eds) Third international symposium on flood defence, Nijmegen, 25-27 May 2005. Floods, from defence to management. Symposium papers. Balkema, Leiden, pp 763-769. http://www.wldelft.nl/rnd/intro/intro/innovation.html\{\#\}planning-kit

Van Waveren RH, Groot S, Scholten H, Van Geer F, Wösten H, Koeze R et al (1999) Good modelling practice handbook. Foundation for applied water research (STOWA) Report 99-05. Dutch Department of Public Works, Institute for Inland Water Management and Waste Water Treatment (RIZA) Report 99-036. http://informatics.wur.nl/research\{\%\}20projects/pub-pdf/gmp.pdf

Verbeek M, Van Delden H, Wind HG, De Kok JL (2000) Towards a generic tool for river basin management-problem definition report-phase 1. German Federal Institute of Hydrology, Koblenz, Germany. http://elise.bafg.de

Verbeek M, Wind HG (2001) Improving control in water management, meeting conditions for control with the ISI-approach. Water Resour Manag 15:403-421. doi:10.1023/A:1015560322043

Vinhas L, De Souza RCM, Câmara G (2003) Image Data Handling in Spatial Databases. Paper presented at the 5th Brazilian Symposium on GeoInformatics, GeoInfo2003. Campos do Jordão, São Paulo, Brazil, 3-5 November 2003

Volk M, Hirschfeld J, Schmidt G, Bohn C, Dehnhardt A, Liersch S et al (2007) A SDSSbased ecological-economic modelling approach for integrated river basin management on different scale levels-the project FLUMAGIS. Water Resour Manage 21:2049-2461. doi:10.1007/s112690079158

Walker DH (2002) Decision support, learning and rural resource management. Agric Syst 73:113127. doi:10.1016/S0308-521X(01)00103-2

Westmacott S (2001) Developing decision support systems for integrated coastal management in the tropics: is the ICM decision-making environment too complex for the development of a useable and useful DSS? J Environ Manage 62:55-74. doi:10.1006/jema.2001.0420

$\mathrm{Xu}$ Y, Mynett AE (2006) Application of uncertainty and sensitivity analysis in river basin management. Water Sci Technol 53(1):41-49. doi:10.2166/wst.2006.006

Zeigler BP, Praehofer H, Kim TG (2000) Theory of modeling and simulation. Elsevier, USA

Zhu X, Dale AP (2000) Identifying opportunities for decision support systems in support of regional resource use planning: an approach through soft systems methodology. Environ Manage 26(4):371-384. doi:10.1007/s002670010094 